\title{
DIGITAL PERFORMANCE INDICATORS IN THE EU
}

\author{
Gunta Grinberga-Zalite, Joanna Hernik \\ Latvia University of Life Sciences and Technologies, Latvia \\ West Pomeranian University of Technology, Poland \\ gunta.grinberga@1lu.lv
}

\begin{abstract}
Today technological progress is reshaping global economic development and changing the overall welfare of societies. Therefore, it is important to assess challenges and readiness of the European Union to use its capacity to ensure that technologies benefit people and bring them towards more inclusive societies enhancing opportunities to use artificial intellect for making health, education, agriculture, services and manufacturing industries more efficient and user friendly. The Digital Economy and Society Index analyses the digital performance of the EU Member States across five main dimensions: connectivity, human capital, use of internet, integration of digital technology, digital public services. However, despite intention to jointly develop Digital Single Market, the gap between the EU top digital countries and less digitally advanced countries remains large. The aim of this paper was to evaluate the digital performance indicators of the EU countries, in particular focusing to Poland and Latvia to assess their progress and potential of their human capital's digital skills. The research is based on theoretical literature studies on industrial revolution stages, European Union Commission documents, indexes and publications available in relevant public institutions such as ministries and industry reports. The research employed monographic method, analysis and synthesis methods as well as graphical data analysis. The research results give evidence that currently Poland's human capital is significantly better prepared for making use of future digital economy challenges than Latvia's human capital, and there is a close link between countries' R\&D expenditures proportion of GDP and their human capital's readiness to integrate in digital economy.
\end{abstract}

Key words: digital economy, competitiveness, Poland, Latvia.

\section{Introduction}

Klaus Schwab who is the founder and executive chairman of the World Economic Forum is aware that today the world is at crossroads due to the fact that more often society expresses its disappointment with national policies and global economics that are incapable to tackle the negative externalities of global economy future development. There externalities affect the environment pollution, social inequality, global immigration, culture clash etc. that results in emergence of populism and many other negative side-effects (radicalism, ignorance, apathy), which significantly threatens the global competiveness of Europe. Thus public trust in European business, governments, mass media and civil society has dramatically fallen during the last couple of years (Schwab, 2017). National governments are indeed under pressure to find appropriate regulations to control rapidly growing technologies such as artificial intellect, biotechnologies, innovative materials and big data analytics with all their exploitation consequences.

Since the $18^{\text {th }}$ century, the global society has already been exposed to three industrial revolutions. In each of them, technology, political systems and society were forced to evolve thus fully transforming national economy industries and society values. The first industrial revolution is associated with Great Britain's textile industry that experienced enormous growth owing to invention of steam engine, followed by mechanization of other industries, development of more efficient transportation, distribution, exchange, communication etc. Despite the fact that this technological progress to a large extent contributed to colonialism with its externalities, all in all it made people wealthier and fostered further innovation development in the rich countries. Consequently, in the beginning of the $20^{\text {th }}$ century, there was a wide range of products and services that gradually entered into private households' life (electricity, radio, combustion engine automobiles, TV, airplanes), which can be considered as the second industrial revolution and huge step forward the modern world. In the middle of the $20^{\text {th }}$ century, first digital technologies emerged - computers that enabled people to store, edit, process and transmit digital format information, which was rapidly adopted in all industries of the advanced world economies, thus giving the way to the third industrial revolution. However, the $21^{\text {st }}$ century has put forward new challenges - digital capabilities today are built on the knowledge and systems of previous three industrial revolutions, thus it gives a start to a new level of integrating humans and technologies' capabilities for more efficient products that comply with modern societies' needs. According to Schwab, they include several powerful clusters: artificial intelligence, robotics, additive manufacturing, neuro and bio technologies, new forms of transport (such as e.g. drons) virtual/augmented reality, innovative materials etc.

\section{Materials and Methods}

The aim of the current research is to evaluate the digital performance indicators in the European Union Members States, in particular focusing to Poland and 
Latvia to assess their progress and future potential. The following research tasks were set: 1) to analyse the EU Member States' performance in the World Economic Forum Global Competitiveness Index component 'Digital skills among population'; 2) to analyse the EU Member States' performance in selected Digital Economy and Society Index components focusing on evaluation of human capital's skills; 3 ) to analyse Latvia and Poland's national level activities to strengthen the digital skills of their human capital.

The introductory part of the paper is based on theoretical literature studies on industrial revolution stages. The practical research part is based on European Union Commission documents' analysis, international indexes and national level strategic planning data available in the relevant public institutions such as ministries and industry reports.

The research employed monographic method for theoretical literature studies, analysis and synthesis methods and graphical data analysis that were used in the process of WEF GCI and DESI data interpretation. Digital economy and skilled human capital in the European Union

One of the indicators that is focused on evaluation of the countries' digital performance on the global scale is WEF Global Competitiveness Index (GCI). Since 2018 the index reflects a separate pillar (Pillar 6 - 'Skills'), which among many other index components evaluates the component 'Digital skills among population'. The results of GCI in 2018 gives evidence that such EU Member States as Sweden (among 139 countries ranked in the $1^{\text {st }}$ place) and Finland $\left(3^{\text {rd }}\right.$ place) today are at the top followed by the Netherlands ( $4^{\text {th }}$ place) and Estonia $\left(10^{\text {th }}\right.$ place). The lowest ranks among the EU Member
States are taken by Poland $\left(68^{\text {th }}\right.$ place $)$, Spain $\left(71^{\text {st }}\right.$ place $)$, Greece $\left(72^{\text {nd }}\right.$ place $)$, Croatia $\left(108^{\text {th }}\right.$ place $)$ and Hungary $\left(115^{\text {th }}\right.$ place). Such situation suggests that despite European Commission efforts to shape the EU's Digital Single Market Strategy that would maximize the growth potential of the European digital economy so that every European can enjoy its full benefit, the real situation reveals dramatic differences in the level of digital skills development among Members States. Since the economy and society of Europe need to make the most of digital, annual comparison of the Member States progress in digital performance is taken very seriously. The Digital Economy and Society Index (DESI) is a composite index that annually aggregates 30 relevant indicators on Europe's digital performance and analyses the evolution of the EU Member States, across five main dimensions: Connectivity, Human Capital, Use of Internet, Integration of Digital Technology, Digital Public Services (Digital Single..., s.a.). In this index, the weighted averages of these five dimensions are as follow: connectivity (25\%); human capital $(25 \%)$; use of internet $(15 \%)$; integration of digital technology $(20 \%)$; digital public Services $(15 \%)$. As reflected in Figure 1, during the last five years EU average values of the five dimensions indicate a positive trend.

In DESI, the Human Capital dimension measures the skills needed to take advantage of the opportunities offered by digital economy. The Figure 2 shows that the performance of the basic and advanced digital skills in 2018 among the Member States significantly differ. Latvia and Poland are among those countries that lag behind the EU-28 average. No doubt, in a modern workplace digital skills are already highly demanded and in the future digital skills will be

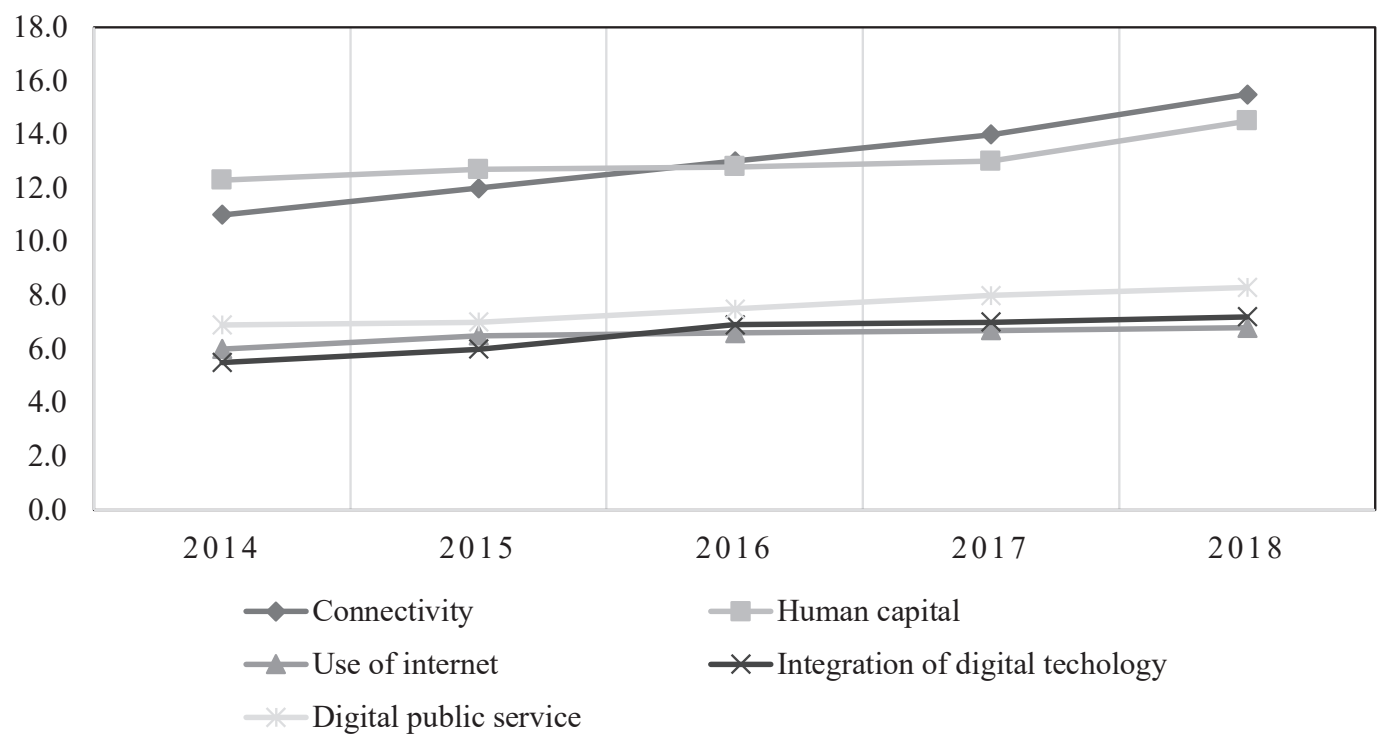

Figure 1. The dynamics of DESI five dimensions in the EU in 2014-2018 (weighted score). Source: The Digital Economy and Society Index, https://ec.europa.eu/digital-single-market/en/desi. 


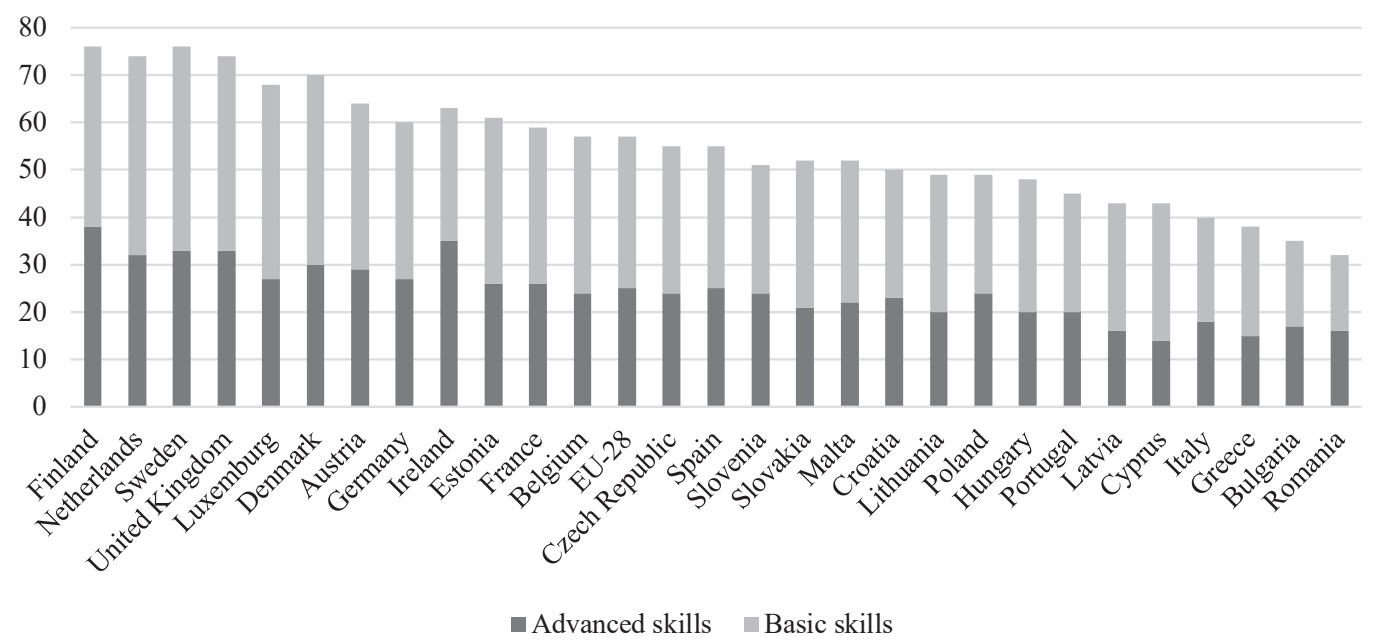

Figure 2. Basic and advanced skills of human capital in the EU in 2018 (weighted score).

Source: The Digital Economy and Society Index, https://ec.europa.eu/digital-single-market/en/desi.

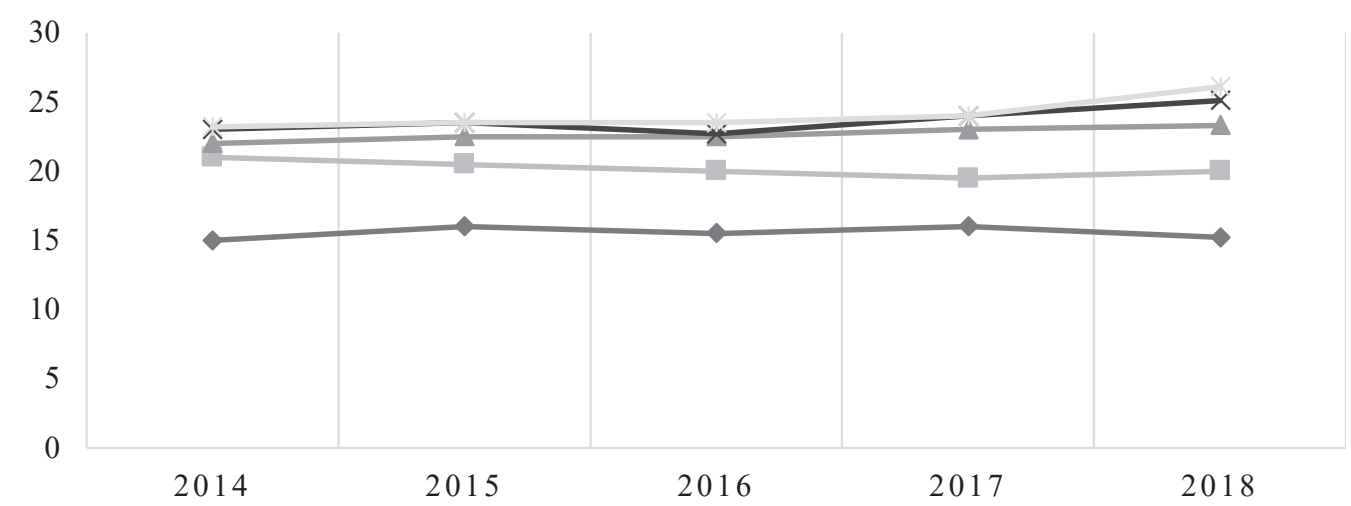

Figure 3. The dynamics of basic and advanced skills' development of the human capital in the EU-28, the Baltic States and Poland in 2014-2018 (weighted score).

Source: The Digital Economy and Society Index, https://ec.europa.eu/digital-single-market/en/desi.

even more vital. In the UK, already in 2015 the House of Lords stated that digital skills should be taught as a third core subject, and treated with same importance as numeracy and literacy Accordingly, the future competitiveness of the EU depends on its human capital's ability to master new skills and thus seize opportunities in digital environment to be able to contribute to the overall development of future economic sectors.

In fact, the closer insights of the advanced skills development in the EU-28 average, the three Baltic States and Poland suggest that all of them except Estonia have shown rather modest results (Figure 3).

The dimension 'integration of digital technology' evaluates the digitisation of businesses and e-commerce. Thus, by adopting digital technologies, enterprises can increase efficiency, cut down costs and better access their clients and business partners. Accordingly, the internet as a sales outlet enables better connection with export potential markets and provides opportunities for growth. The situation in 2018 reveals that business digitalization and e-commerce in Latvia and Poland naturally lag behind the EU-28 average (Figure 4).

However, keeping in mind the evaluations of the GCI-2018, the high evaluation of DESI in 2018 suggests that Spain, despite its low digital skills of population ( $72^{\text {nd }}$ place) has achieved comparatively high integration of digital technology in business and is among the best in the EU, while Estonia despite its high $10^{\text {th }}$ place significantly lags behind the EU-28 average, which is worth exploring.

Potential of the European Union digital economy in the future

According to CEEMET European Tech and Industry Employers, today Europe has the most educated workforce in all its history. Nevertheless, a serious barrier to developing digital competence is closely linked to the lack of adequate digital skills and competences in the education systems. Moreover, due to the rapid integration of new technologies such as artificial intellect, biotechnologies, innovative 


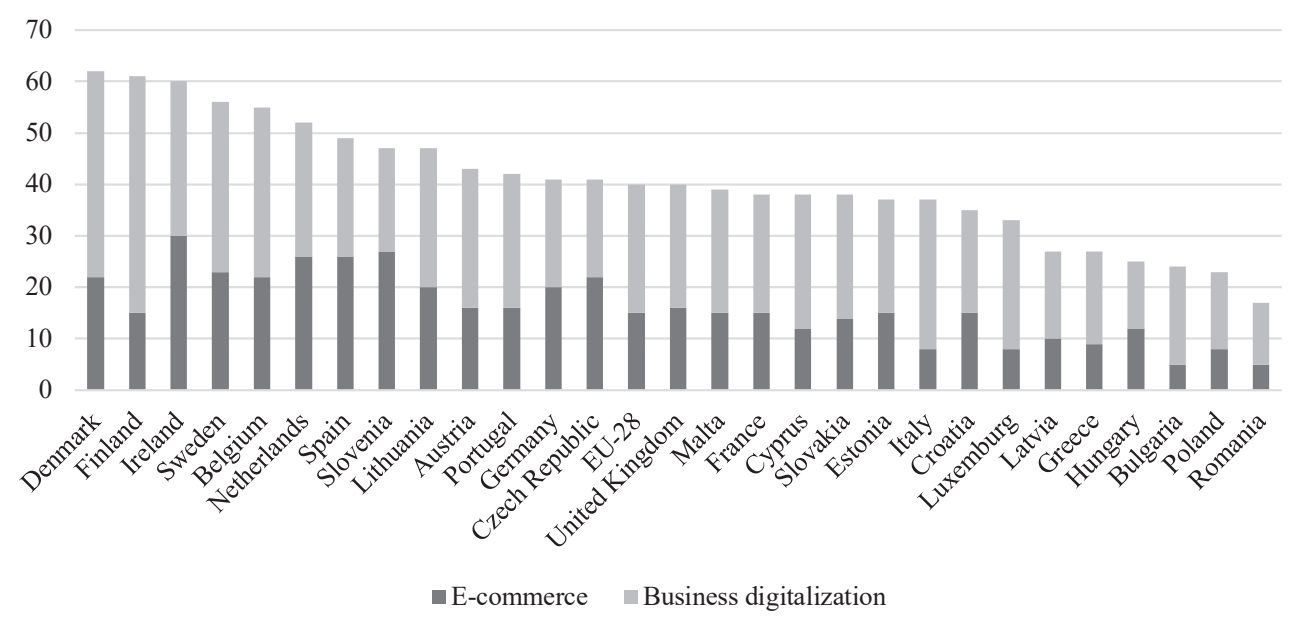

Figure 4. Integration of digital technology: business digitalization and e-commerce in the EU in 2018 (weighted score).

Source: The Digital Economy and Society Index, https://ec.europa.eu/digital-single-market/en/desi.

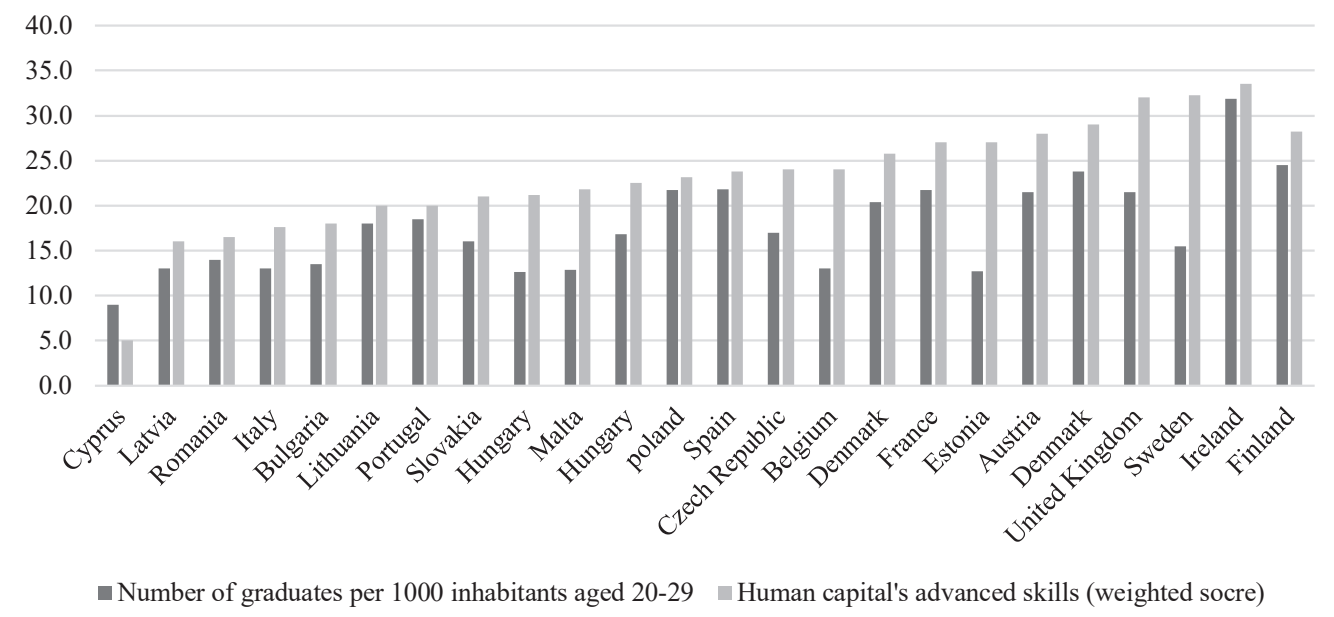

Figure 5. The number of STEM graduates per 1000 inhabitants and advanced skills evaluation of human capital (weighted score) in the EU in 2018.

Source: The Digital Economy and Society Index, https://ec.europa.eu/digital-single-market/en/desi.

materials and big data analytics in our life, EU's digital businesses are desperately short of STEM graduates. STEM is a curriculum based on the idea of educating students in four specific disciplines science, technology, engineering and mathematics in an interdisciplinary and applied approach.

According to the Figure 5, future estimates for digital economy development currently look better in Poland than in Latvia, while the absolute leaders of the EU are Finland and Ireland. The situation of Sweden, however, suggests that high level of population's advanced skills can be achieved without increased number of STEM graduates, which is worth exploring. Whereas Ireland has the largest number of STEM graduates per 1000 inhabitants, but in previously analysed GCI-2018 evaluation of digital skills of population Ireland is ranked only in $19^{\text {th }}$ place, lagging behind Denmark, Estonia and Germany.
Both Poland and Latvia have emphasized the importance of digital skills development in their longterm strategic documents - 'Poland 2025: Europe's new growth engine' and 'Sustainable development of Latvia until 2030'. Accordingly, Polish and Latvian governments have involved their relevant Ministries in achieving these goals by setting specific tasks for them.

Since 2017, Polish government has been implementing the 'Operational Program Digital Poland'. The objectives of this program are:

- eliminating territorial differences in the ability to access high; bandwidth broadband internet;

- high availability and quality of public e-services;

- digital access to public sector information;

- digital access to scientific resources;

- training activities for the digital competences development. 
In Latvia, the Information Society Guidelines for 2014-2020 have defined the following objectives:

- coordination and development of ICT projects according to e-GOV architecture;

- public service governance, quality regulation;

- implementation of Official electronic address;

- implementation of eiDAS (electronic identification, authentication and trust services);

- expand network of Unified Customer Centres;

- e-Skills and e-Awareness program.

Since 2015, extensive and interrelated national research projects have been supported by the National Research Program 5.2. 'Economic Transformation, Smart Growth, Governance and Legal Framework for the State and Society for Sustainable Development a New Approach to the Creation of a Sustainable Learning Community (EKOSOC-LV)', which also have resulted in scientific publications (Pelse \& Lescevica, 2016; Pelse et al., 2018) revealing Latvia's smart specialization aspects and current problems (which are closely related with the lack of qualified human capital) that hinder Latvia's smart specialization in Latvia's regions.

Both in Poland and in Latvia, there are specially developed frameworks for SMEs digital promotion policy and e-service development in public and private sectors. According to Kitchin et al. (2015), digital development also means wider access to different data. And the problem is who should finance this kind of services. There is no straight forward solution to funding digital data repositories that are not wholly core funded, with a number of general and specific challenges facing each repository, and each funding model having strengths and weaknesses. Moreover, education systems in Latvia and Poland currently are facing major reforms guided towards adaptation of study content and process to the changes in global economy. Digital transformation of businesses and public institutions depends on digital innovations. So the focus should be on encouraging various types of technological innovations, even on a small scale (Khin \& CF Ho. 2018).

In case of Poland, in 2018 compared with the other nine countries that joined the EU in 2004 (Cyprus, the Czech Republic, Estonia, Hungary, Latvia, Lithuania, Malta, Slovakia, and Slovenia), it was among the best regarding the number of STEM graduates and human capital with advanced skills in this group of countries. Poland's progress is almost in line with the Czech Republic and lagging behind only Estonia, which is a convincing leader among these countries. The situation of Latvia is not so optimistic. Latvia's performance in relation of STEM graduates and its human capital development is poor, and only Cyprus currently has lower evaluation of these indicators. In authors opinion, the explanation to this problem is closely linked with the countries' R\&D expenditures of GDP, which is annually reflected among other countries' innovation capacity indicators in the $12^{\text {th }}$ pillar of the WEF GCI. In the countries with the best developed skills of human capital, the R\&D expenditures in 2018 were significantly high - in Sweden $-3.3 \%$ and in Finland $-2.9 \%$ of GDP but in Ireland and Estonia $1.5 \%$, which is also considerably higher compared with Poland and Lithuania, which allocate accordingly only $1 \%$ of their GDP expenditures to R\&D. However, the worst situation in 2018 was observed in Romania and Cyprus ( $0.5 \%$ of GDP) and Latvia ( $0.6 \%)$.

\section{Conclusions}

1. The theoretical studies of the three experienced industrial revolutions give evidence that technological progress always exposes existing technology, political systems and society to inevitable changes thus transforming national economy industries and society values. Therefore, today target-oriented and meaningful training of human capital's digital skills is important for any country regardless of its national economy specialization.

2. Despite intention to jointly develop Digital Single Market, the digitalization potential's gap between the EU wealthier countries and less wealthy countries remains large. Generally, the research results reveal that North European countries of the EU - Finland, Sweden, Denmark, Estonia and Ireland and the Netherlands showed best performance in 2018. The results of Lithuania and Latvia and Poland currently lag behind the EU-28 average. However, Poland's human capital is significantly better prepared for making use of future digital economy challenges as its number of STEM graduates on 1000 inhabitants is significantly larger than in other Member States such as Latvia, Romania, Cyprus, Italy, Hungary, Slovakia, Malta, Bulgaria.

3. The analysis of R\&D expenditures in $\%$ of GDP gives evidence that wealthier Member States allocate more than $3 \%$ of their GDP to R\&D, while such countries as Latvia, Cyprus and Romania in 2018 allocated only $0.5-0.6 \%$ of their GDP to $\mathrm{R} \& D$ in their countries. Therefore, their future digital potential, namely human capital with advanced skills, is seriously threatened unless current national political guidelines are changed.

\section{Acknowledgements}

The paper was supported by the National research programme 'Latvian Heritage and Future Challenges for the Sustainability of the State" project "Challenges for the Latvian State and Society and the Solutions in International Context (INTERFRAME-LV)". 


\section{References}

1. Digitalization and the World of Skills and Education. CEEMET6. - European Tech and Industry Employers. Retrieved March 13, 2019, from https:/www.ceemet.org/sites/default/files/ceemet_ digitalisation_and_skills_report_spreads.pdf.

2. Khin, S., \& $\bar{C} F$ Ho, T. (2018). Digital technology, digital capability and organizational performance: A mediating role of digital innovation. International Journal of Innovation Science. DOI: 10.1108/IJIS-082018-0083. Retrieved March 12, 2019, from https://www.emeraldinsight.com/doi/abs/10.1108/IJIS-082018-0083?fullSc=1\&journalCode=ijis.

3. Kitchin, R., Collins, S., \& Frost, D. (2015). Funding models for open access digital data repositories. Online Information Review, Vol. 39, Issue: 5, pp. 664-681. DOI 10.1108/OIR-01-2015-0031. Retrieved July 11, 2019, from https://pdfs.semanticscholar.org/eb89/4636399398da2acc280e649f12b7d0ec377b. pdf.

4. Pelse, M., \& Lescevica, M. (2016). Smart specialisation assessment in Latvia. Proceedings of the International scientific conference 'Economic science for rural development', Jelgava, April 21-22, 2016. Latvia University of Agriculture. Jelgava, No. 42: Integrated and Sustainable Regional Development. Production and Co-operation in Agriculture. pp. 126-131. DOI: 10.1515/lpts-2016-0024.

5. Pelse, M., Ziedina D., Aleksejeva L., \& Bitmane, M. (2017). Cooperation as a sustainable factor influencing innovation in regional development: the case of the bioeconomy in Latvia. Journal of Security and Sustainability Issues. International Entrepreneurial Perspectives and Innovative Outcomes. Vol. 7(3), (2018), pp. 581-590. DOI: 10.9770/jssi.2018.7.3(17).

6. Poland 2025: Europe's new growth engine. (2015). Mc Kinsey Company. W. Bogdan, D., Boniecki, E., Labaye, T. Marciniak, M. Nowacki. Retrieved March 13, 2019, from https://www.mckinsey.com/ /media/ mckinsey/business $\% 20$ functions/economic\%20studies $\% 20$ temp/our\%20insights/how\%20poland $\% 20$ can $\% 20$ become $\% 20 \mathrm{a} \% 20$ european $\% 20$ growth\%20engine/poland $\% 202025$ full_report.ashx.

7. Schwab, K. (2017). The fourth industrial revolution. Published January $11^{\text {th }} 201 \overline{6}$ by the World Economic Forum. Kindle Edition, 198 p. DOI: 10.5430/ijfr.v9n2p90.

8. Sustainable development of Latvia until 2030 (2010). Saeima of the Republic of Latvia. Retrieved March 13, 2019, from https://www.pkc.gov.lv/sites/default/files/inline-files/LIAS 2030 en_1.pdf.

9. The Digital Economy and Society Index. The European Commission: Digital Single Market. Digital Economy and Society. Retrieved March 13, 2019, from https:/ec.europa.eu/digital-single-market/en/desi.

10. The Global Competitiveness Report 2018. The World Economic Forum. Retrieved March 13, 2019, from https://www.weforum.org/reports/the-global-competitveness-report-2018. 